This item was submitted to Loughborough's Research Repository by the author.

Items in Figshare are protected by copyright, with all rights reserved, unless otherwise indicated.

\title{
Axle whine phenomenon in light trucks: a combined numerical and experimental investigation
}

PLEASE CITE THE PUBLISHED VERSION

http://dx.doi.org/10.1177/0954407011401302

PUBLISHER

Professional Engineering Publishing (now published by Sage)

VERSION

AM (Accepted Manuscript)

LICENCE

CC BY-NC-ND 4.0

\section{REPOSITORY RECORD}

Koronias, George, Stephanos Theodossiades, Homer Rahnejat, and T. Saunders. 2019. "Axle Whine Phenomenon in Light Trucks: A Combined Numerical and Experimental Investigation”. figshare. https://hdl.handle.net/2134/13347. 
This item was submitted to Loughborough's Institutional Repository (https://dspace.lboro.ac.uk/) by the author and is made available under the following Creative Commons Licence conditions.

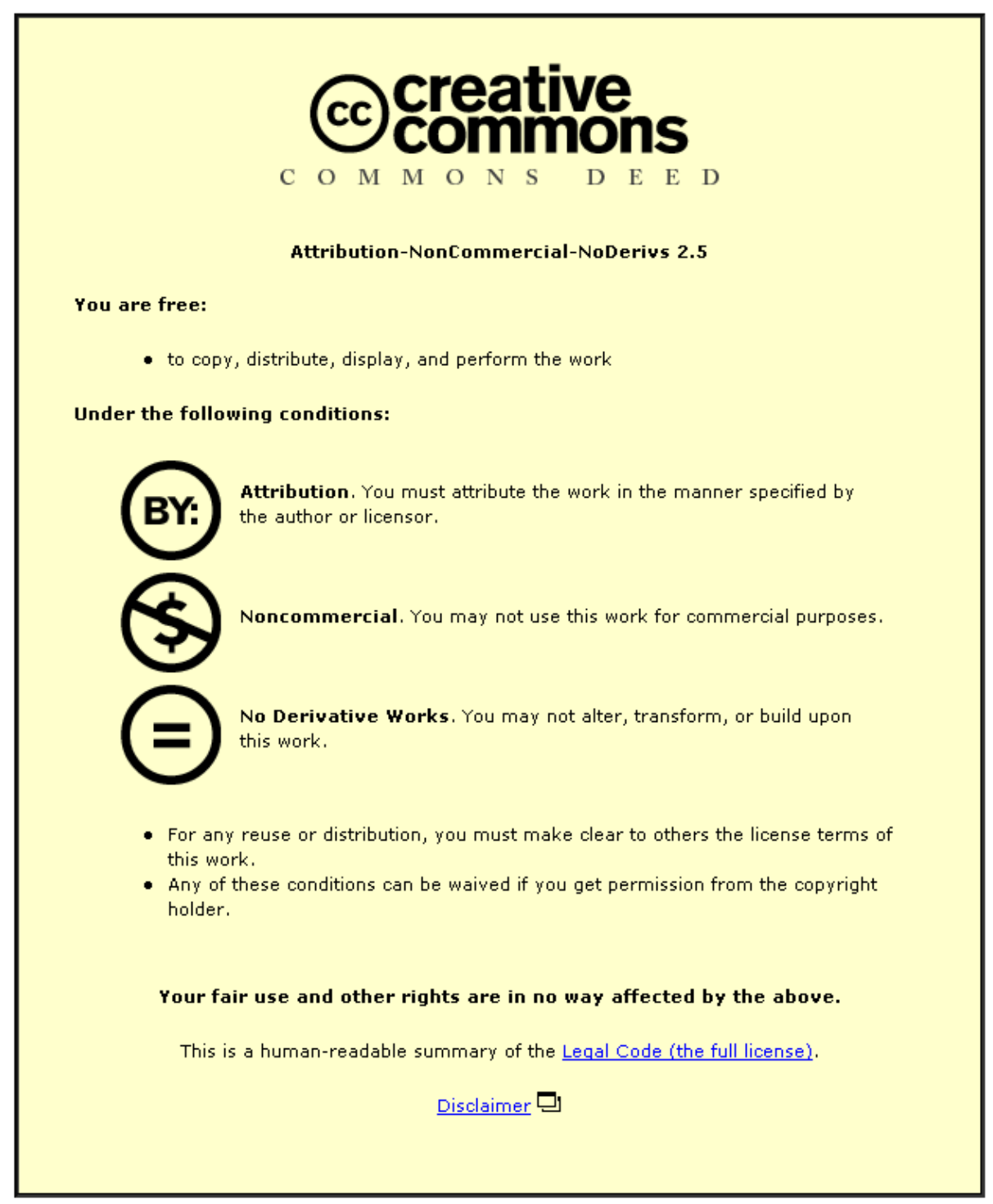

For the full text of this licence, please go to: http://creativecommons.org/licenses/by-nc-nd/2.5/ 


\title{
Axle whine phenomenon in light trucks: a combined numerical and experimental investigation
}

\author{
G. Koronias* ${ }^{*}$ S. Theodossiades ${ }^{{ }^{1}}$, H. Rahnejat ${ }^{*}$ and T. Saunders ${ }^{\#}$ \\ Wolfson School of Mechanical \& Manufacturing Engineering, \\ Loughborough University, Loughborough, UK
}

${ }^{1}$ Corresponding Author: S.Theodossiades@lboro.ac.uk

\begin{abstract}
Axle whine is a continuous, steady state tonal sound, emitted from the differential unit's hypoid gears. It is essentially induced by torque variations. This can be as a result of resonant conditions or torque fluctuations caused by engine order vibrations, compounded by gear transmission error. The principal mechanism of gear whine noise generation is, therefore, through transmission of vibration from the gear shafts and bearings to the differential housing, which is radiated as noise. Furthermore, interactions between the differential unit, axles and driveshafts often generate excessive tonal noises, which are the result of coupled bending and torsional resonances of assembled components. These resonances induce a magnification effect upon the noise source itself through exciting the gear shafts and distorting the alignment of the gear sets. Axle whine noise has become an important Noise, Vibration and Harshness (NVH) concern, because of the nature of the noise, further compounded by the human aural system, which is highly sensitive in tonal memory. The result is a continuously increasing warranty costs or use of expensive palliatives to mitigate the phenomenon.

In this paper, a combined experimental and numerical investigation of axle whine in a rear wheel drive light truck is presented. The aim is to reveal some root causes of the drivetrain's NVH behaviour, which can be related to the amplification/reduction of axle whine vibration and noise. Correlation of the experimental results with the vibration modes of the drivetrain has shown that for vehicle coasting conditions a number of modes are excited, which can interact with the vibrations of the hypoid gear pair. Finally, some light is shed on the role that differential bulk oil temperature plays in the severity of the ensuing vibration.
\end{abstract}

Keywords: axle whine, multi-body dynamics, drivetrain modes of vibration, airborne/structure borne noise

\section{Introduction}

The radiation of noise from vehicle power train has become a major concern and a perceived quality issue in recent times. This has provided an impetus for the investigation of various Noise, Vibration and Harshness (NVH) problems. As the power stroke takes place, depending on the firing order and number of cylinders, the crankshaft undergoes torsional oscillations, which are transmitted through the driveline [1]. This vibration signature, which also depends on the selected gear, is 
transmitted to the propeller shafts and from the power train mountings to the vehicle body. There are several possible excitation sources for the differential unit and the axle. Some are induced by the engine and the transmission, as already described. Others include road excitation transmitted through the wheel hubs and others as the result of irregular meshing of the gear pairs in the differential unit itself (transmission error, gear surface irregularities, impacts). Some vibrations can lead to airborne and/or structure-borne axle whine noise. This is a continuous, steady state tonal sound that is emitted from the differential unit, manifesting itself mostly at the gear meshing frequency and its harmonics [2]. The phenomenon is essentially torqueinduced, either as a resonant condition or due to torque fluctuations, caused by engine order harmonics, compounded in the presence of transmission error (i.e. the deviation from idealised meshing) [3]. Experimental measurements taken from vehicles have revealed significant correlation between noise in the passenger compartment and vibration at the differential housing. Yet little correlation has been found with vibrations at chassis mounts. The principal mechanism of whine noise generation is, therefore, through transmission of vibration from the gear shafts and bearings to the differential housing, which radiates noise [2, 3]. Although the resulting whine noise in the cabin is relatively low in comparison to road noise levels, it is disconcerting because of its higher frequency content, with often dominant amplitude and frequency modulation effects due to mounting eccentricities, teeth contact stiffness variations and manufacturing errors. Furthermore, interactions between the differential unit and driveshafts often generate excessive tonal noises, which are the result of coupled bending and torsional component resonances. These resonances have a magnification effect on the underlying source itself. They tend to excite the gear shafts and distort the alignment of the gear sets. Whine noise is further compounded by the human aural system, which is highly tonal-memory sensitive, but has a more limited amplitude memory [4]. Therefore, vehicle occupants tend to become sensitized to this type of noise and, even if attenuated, still sense the noise and remain concerned with regard to possible failure repercussions.

Axle gear whine has been investigated experimentally [5]. Global mode shapes of the axle which contribute to whine due to airborne noise were identified (torsional and bending modes). A more generalised approach to investigating axle whine was followed in [6], where material was removed from the interior of a vehicle and internal noise was recorded until axle whine noise "hot spots" were identified. A two wheel dynamometer was used in the tests as in [7]. It was found that the higher order frequencies and more specifically the torsional resonant vibrations of the propeller shafts are responsible for the axle noise. In another study, transfer path analysis was employed in a vehicle, as well as Finite Element Analysis (FEA) to note that reinforcing the lower control arm bracket (beam element connecting the wheel hub with the differential unit surround) resulted in a reduction in axle noise [8]. Damping or stiffening the axle in certain locations can also reduce the radiated noise level [9].

The Transmission Error (TE) in the hypoid gear pair induces interior noise through structural paths [10]. Improvement to structure-borne noise can be achieved using softer cabin mounts to isolate the passenger compartment from the frame that supports it [6,11]. Transmissibility path analysis was employed when studying the best or worst case scenarios affected by TE. Using commercial FEA software, it was noted that body mounts and the sub-frame system significantly affect gear whine [12]. The importance of airborne noise during axle whine conditions has been highlighted in $[5,13]$. It was also found that axle whine is related to manufacturing variability [14].

A variability reduction method has been applied in order to select the most suitable gear pairs (in terms of NVH capabilities) from the production line [14]. The variability was narrowed in the study of the following parameters: gear manufacturing machines, hobbing cutters, machine operators, rolling dies, the in-service life of cutters and orientation of the gears. It was found that although these parameters do play a role in the axle whine performance of the gear pairs, the identified optimum 
values of existing gear parameters do not reduce axle whine dramatically. It is noteworthy that the above research was based on gear pairs of an automatic transmission prone to whine.

Another investigation dealt with an analytical simulation approach for studying the variability introduced by gear manufacturing errors [15]. Gear profile parameters such as contact ratio, pitch error and crowning were studied (with and without loading) with respect to the influence on the static transmission error of hypoid gears. These characteristics play the most influential role in tooth dimensions, tooth surface modification and manufacturing error. The analysis clarified the effect of each factor on gear noise, making it possible to prepare guidelines for optimal design of gear dimensions and tooth surface modification under various conditions.

Analysis of the NVH behaviour of a light truck [16] similar to the one in the current work suggested that each vehicle body type responds with a different degree of sensitivity, but ultimately the source of gear whine remained the high amplitudes of axle structural vibration, resulting from manufacturing variability of hypoid gear quality. The investigation studied the isolated and combined effect of reducing variability in static transmission error. A separate capability study for static transmission error on two final drive ratios (3.77 and 4.27) showed that variability was considerably higher on the 3.77 gear ratio. This phenomenon was explained when the static transmission error was measured for two batches of gears, one with lapped surfaces on an Oerlikon machine and the other on a more modern CNC controlled machine. The transmission error results, as measured on the original Oerlikon single flank test machine, clearly indicated that the variability was greatly reduced on the CNC machine but the mean transmission error value was still higher than that measured for the 4.27 final drive ratio hypoid gear pair.

A model that can assess drivetrain $\mathrm{NVH}$ phenomena was presented in [17]. A multibody dynamics method was used, coupled with FE analysis, which allowed the study of highly non-linear dynamics phenomena related to the gear teeth contacts in a gear train. The authors proposed a specific strategy for gear train optimisation through sensitivity analysis. Similarly, an elasto-multi-body dynamics approach was employed in [18] for the identification of vibration modes under impact-induced oscillations in drive trains. The elastic degrees of freedom were reduced using the Craig-Bampton method. Finally, the Inverse Boundary Element Method (IBEM) has been employed for the identification of vibration modes contained within axle whine noise spectrum [19-21].

This paper presents a combined experimental and numerical investigation of axle whine phenomenon in a light truck. A direct qualitative correlation of a complete drivetrain model to the behaviour of a test vehicle is made. The model developed is an integrated tool to study axle whine, since it includes the main deformable/compliant components of the drivetrain system, coupled with a hypoid gear pair model which includes backlash and static transmission error and can be used to study vehicle response under drive and coast conditions [22]. The combination of the above allows for a detailed characterisation of the axle whine phenomenon.

First, the virtual prototype of the vehicle's drive train and the set-up of the experimental investigations are described. Next, a comparison is made between the numerical and experimental findings, with the aim of shedding some light on the interaction of the drive train's vibration modes with the ensuing axle whine noise. The agreement found between the main frequencies observed in the experimental measurements and the mode shapes captured numerically is within reasonable bounds. Finally, the main conclusions from this work are presented with suggestions for further experimental and numerical investigations. 


\section{Multi-Scale Multi-Physics Driveline Model}

The virtual prototype of the drive train system of a rear wheel drive light truck (similar to the drive train subjected to experimental measurements) is developed in a multibody dynamics' environment. The model comprises all power train components from the transmission output shaft through the driveline and differential unit to the rear axle (Figure 1). The ADAMS commercial code has been used. The model also contains the reaction points, defined as the points where resistance to motion is encountered. These include the rear suspension system, which in the case of light trucks (as in the case under investigation) and lorries is invariably a Hotchkiss leaf spring live axle assembly. The other reaction points are the driveline centre bearing connection to the vehicle floor pan (considered as rigid in the current analysis) and the rear tyres-to-road contact patches. The resistance at the contact patches is important when studying shuffle, because of traction, but not for axle whine, which occurs when the vehicle is coasting at relatively high speeds. Therefore, the drive train model is quite a complex assembly, comprising various constraining elements, such as joints and non-linear restraining or structural compliances, gear backlash and stiffness/damping between the teeth of the differential unit hypoid and bevel gear pairs.

The inertial dynamics of the multi-body system are represented by constrained Lagrangian dynamics. Components which are expected to undergo elastic deformations relative to others during the drive train operation have been modelled as flexible components, using FEA techniques in the Patran/Nastran environment. The Craig-Bampton component mode synthesis method has been employed to reduce the total number of degrees of freedom, thus rendering a manageable model in terms of computation times and the required memory size. The connection of the flexible bodies to the rigid bodies of the drivetrain model is achieved using attachment points or master nodes, through RBE2 elements [18]. The generated super-elements store a number of natural modes for the purpose of obtaining the actual mode shapes when the system is dynamically loaded throughout the spectral region of interest from $50 \mathrm{~Hz}$ to $3000 \mathrm{~Hz}$. Therefore, the elasto-multi-body model comprises 23 moving parts of the drive train assembly and suspension system and has 9 flexible parts (the propeller shafts, the axles, the Hotchkiss leaf springs and the rear axle half-shafts), yielding 334 modes of vibration. The overall degrees of freedom are 299 (19 degrees of freedom are purely rigid body motions).

\section{Experimental Measurements}

Experimental measurements under subjectively identified axle whine conditions were carried out in a rear wheel drive light truck with long wheel base and high headroom, which was instrumented as shown in Figure 2. The vehicle is also equipped with a dual mass flywheel. The pertinent vehicle data are provided in Table 1. The instrumentation included three free field microphones; two of which were installed inside the vehicle cabin and the other attached to the vehicle underbody, facing the differential unit (Figure 2). Three accelerometers were also fixed to the differential unit. These were orientated as follows: one in the z-direction (vertical displacement), another in the $y$-direction (lateral transverse displacement) and the other in the $x$ direction (longitudinal or fore and aft motion). A thermocouple was inserted into the differential oil sump to measure the oil temperature. Finally, an encoder was mounted between the rear driveshaft tube and the differential inertial ring in order to capture the pinion shaft's real speed.

The vehicle was warmed up to the normal operating condition, indicated by the thermocouple inserted into the differential casing. Measurements were initiated with the bulk oil temperature exceeding $25^{\circ} \mathrm{C}$. The vehicle was then driven until the whine noise was subjectively identified. Under the identified condition, the encoder recorded a vehicle speed of around $60-62 \mathrm{~km} / \mathrm{h}$. Whine was noted around these speeds under 
coast condition with the $5^{\text {th }}$ gear speed engaged. The data acquisition sampling rate was set at 8000 samples/second. Therefore, according to the Nyquist criterion, spectral contributions up to $4 \mathrm{kHz}$ are considered as reliable. Higher contributions are deemed to be subject to aliasing.

The time history signals obtained were first calibrated to convert from voltage output to physical quantities; acceleration, velocity and sound pressure level. The signals were observed with emerging repetitive patterns and windowed around regions of interest, with sample records suitable to undertake wavelet analysis in order to identify the significant transient spectral contents. The Continuous Wavelet Transform (CWT) was used to decompose the acquired signals into wavelets (small, localised oscillations in time). The advantage of CWT vis-a-vis Fourier transformation is that the latter decomposes a signal into infinite length sine and cosine series, effectively losing all the time-localised information. The CWT is used to construct a time-frequency representation of a signal that offers accurate time and frequency localization [23].

For a given time series $X$ (with values $x_{n}$ at time indices $n_{2}$ separated by a constant time interval $d t$ ), CWT is the convolution of the data sequence with the mother (root) wavelet function $\Psi_{0}[24]$ :

$$
\begin{aligned}
& W_{n}(s)=\sum_{n^{\prime}=0}^{N-1} x_{n^{\prime}} \sqrt{\frac{\delta t}{s}} \Psi_{0}^{*}\left[\frac{\left(n^{\prime}-n\right) \delta t}{s}\right] \text { (in time domain) } \\
& W_{n}(s)=F F T^{-1}\left[\sum_{n^{\prime}=0}^{N-1} \hat{x}_{k}\left(\sqrt{\frac{2 \pi s}{\delta t}} \hat{\Psi}_{0}^{*}\left(s \omega_{k}\right) e^{i \omega_{k} n \delta t}\right)\right] \text { (in frequency domain) }
\end{aligned}
$$

where, $\hat{x}_{k}=\frac{1}{N} \sum_{n=0}^{N-1} x_{n} e^{-2 \pi i k n}$

and $\omega_{k}= \begin{cases}\frac{2 \pi k}{N \delta t} & : \quad k \leq \frac{N}{2} \\ -\frac{2 \pi k}{N \delta t} & : \quad k>\frac{N}{2}\end{cases}$

In the above equations, the superscript * denotes the complex conjugate, $N$ is the data series length, $s$ is the wavelet scale and $\omega$ is the angular frequency.

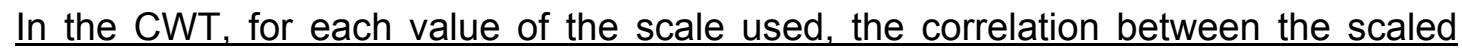
wavelet and successive segments of the data stream is computed. The CWT consists of $\mathrm{N}$ spectral values for each scale used, each of which requires an inverse FFT. Therefore, the CWT computational time and memory requirements are quite significant. However, the benefit is an accurate time-frequency spectrum. Wavelet decomposition uses a function as the analyzing or mother wavelet. The latter is continuous in both time and frequency, which serves as the source function from which scaled and translated basis functions are constructed.

The wavelet mother (root) function used in this work is that of Morlet, which is defined as the following in time and frequency domains, respectively:

$$
\begin{aligned}
& \Psi_{0}(n)=\pi^{-1 / 4} e^{i m n} e^{-n^{2} / 2} \\
& \hat{\Psi}_{0}(s \omega)=\pi^{-1 / 4} H(\omega) e^{-(s \omega-m)^{2} / 2}
\end{aligned}
$$

where $m$ is the wave number and $H$ is the Heaviside step function: $H(x)=\int_{-\infty}^{x} \delta(t) d t$ 
The time-frequency wavelets presented in the paper have been produced using the Autosignal software [23]. These plots depict the frequency content of the acquired signals, as well as the time period through which each spectral contribution persists.

Finally, it was deemed necessary to establish the important and expected spectral contents of vibration from the power train system model. These are subsequently used to identify the experimentally obtained spectral contributions. The test results reported below were at the speed of $242 \mathrm{rad} / \mathrm{s}$, corresponding to the propeller shaft speed of $2310 \mathrm{rpm}$ or approximately $1917 \mathrm{rpm}$ crankshaft speed (the $5^{\text {th }}$ speed gear ratio is 0.83 in the case of investigated vehicle). The engine order (fundamental) is therefore, $32 \mathrm{~Hz}$. The most significant engine order harmonic is the second order at $64 \mathrm{~Hz}$ for the 4-cylinder 4-stroke engine of the test vehicle [1]. The differential hypoid gears' meshing frequency at this driveshaft speed is approximately $347 \mathrm{~Hz}$ (the hypoid pinion has 9 teeth).

\section{$4 \quad$ Results and Discussion}

The first set of measurements presented corresponds to the bulk differential oil temperature of $51^{\circ} \mathrm{C}$. Then, a series of results under similar driving conditions, but at the bulk oil temperatures varying between $55^{\circ} \mathrm{C}$ and $68^{\circ} \mathrm{C}$ were captured.

It is sensible to commence with the microphone data as this provides the annoying effect perceived by the vehicle occupants. Figure 3 shows the wavelet plot of the signal acquired by the rear microphone inside the vehicle cabin, directly above the position of the propeller shaft at the speed operating of $242 \mathrm{rad} / \mathrm{s}(2310 \mathrm{rpm}$ or 38.5 $\mathrm{Hz}$ at $51^{\circ} \mathrm{C}$ of bulk oil temperature). Two significant frequencies are noted throughout the sample record analysed. One is at $70 \mathrm{~Hz}$, which is also noted by the microphone in the vicinity of the driver's in-board ear (Figure 4). This is the second engine order (calculated to be nominally at $64 \mathrm{~Hz}$ ), which has been distorted because the car is coasting and, therefore, its engine speed is constantly changing. The steady state nature of this contribution can be regarded as the airborne background engine noise or low level cabin resonation (low amplitude body boom noise [25]). The cabin longitudinal dimension (x-direction) determines the lowest frequency that can be discerned by the rear microphone. For a cabin length of approximately $5 \mathrm{~m}$ (neglecting reflections):

$$
f=\frac{v}{\lambda}=\frac{330}{5}=66 \mathrm{~Hz}
$$

where $f$ denotes frequency, $v$ is the noise propagation velocity in air $(330 \mathrm{~m} / \mathrm{s})$ and $\lambda$ is the wavelength $(\mathrm{m})$ corresponding to the cabin longitudinal dimension. However, this is not the event of transient nature that has been subjectively perceived by the passengers and attributed to axle whine. The second main contribution in Figure 3 is in the vicinity of the hypoid gear pair meshing frequency $(9$ pinion teeth $\times 38.5 \mathrm{~Hz}=$ $346.5 \mathrm{~Hz}$ ). This has been captured by the rear cabin microphone, but it is absent in the signal recorded by the microphone at the driver's in-board ear (Figure 4) and the outside microphone facing the differential unit (Figure 5). The omission of this frequency in the latter two spectra presents some doubt as to the underlying cause of whine being the hypoid gear pair meshing frequency.

At this point it was deemed necessary to compute the natural frequencies and mode shapes of the drivetrain assembly, using the aforementioned multi-body model in order to identify any correlation with the experimental findings. It was found that the S-bending mode of the Hotchkiss leaf springs occurs at $356 \mathrm{~Hz}$ (Figure 6), which is also very close to the hypoid gear pair meshing frequency, thus clearly exacerbating the effect of meshing due to any misalignment. This can lead to the generation and amplification of whine noise in the vehicle cabin (mainly as a structure-borne event). The issue of attribution can be resolved by referring to accelerometer responses. Figure 7 shows the wavelet plot for the z-axis accelerometer response near the nose 
of the differential unit. This shows a continuous waveform with significant events taking place. It can be clearly seen that both the S-bending mode of the Hotchkiss leaf springs and the meshing frequency are present concurrently.

The mode shape of the drivetrain model at $356 \mathrm{~Hz}$ is its wind-up response (axle and suspension springs). The system unwinds at $509 \mathrm{~Hz}$, as shown in Figure 8, where the corresponding mode shape is presented. With S-bending of leaf springs there is usually some degree of wheel tramp. If this is found to be present, it implies significant leaf spring instability under the test conditions. Note that the mode shape shown in Figure 6 excludes any leaf spring friction, implying that insignificant energy is absorbed by their sliding motion. This enables axle misalignment. Therefore, the $y-$ direction accelerometer signal near the differential nose is quite important. This is shown in the wavelet plot of Figure 9, where a frequency of $240 \mathrm{~Hz}$, which corresponds to the natural frequency of lateral sway of the driveshaft tubes (see the mode shape in Figure 10). This confirms that low frictional S-bending modes of the leaf springs co-exist with higher frequencies within the same short-window spectrum (Figure 7). This combination of events can account for structure-borne noise propagation through the suspension and absorber mounts to the cabin. The frequency of $750 \mathrm{~Hz}$ in the spectrum of Figure 9 can be attributed to the third harmonic of the lateral sway mode of the drivetrain $(240 \mathrm{~Hz})$.

Clearly with significant energy content a higher rear axle "butterfly" mode combined with leaf spring S-bending is also excited at $772 \mathrm{~Hz}$ (Figure 11). The same butterfly type vibration mode has been observed during axle whine conditions in rear wheel drive powertrains by other investigators [26]. Even a higher frequency mode at 1721 $\mathrm{Hz}$ has been noted, being a bending mode of the second driveshaft tube (Figures 7 and 9). This mode has also been noted in the investigation of clonk on the same light truck [16], and it was found to be a significant vibration concern, but not a significant noise radiator.

The effect of the oil sump temperature in the differential unit can be quite significant, particularly as lubricant viscosity is affected significantly, reducing the film thickness and increasing viscous friction as well as in extreme cases asperity/boundary friction when a coherent film of lubricant is not maintained. Any increase in friction of the contacting teeth acts as a dissipation source which would contribute to attenuation of vibration. This means that contributions at meshing frequency and any modal behaviour involving misalignment of rear axle half-shafts should be somewhat attenuated at higher lubricant temperatures. However, there would normally be insignificant attenuation at engine order harmonics and the high structural spectral contributions due to driveshaft's modal behaviour. The analysis of a volume of data acquired by the accelerometers (at different bulk oil temperatures) in a similar manner to the representative sample reported above yield the key findings shown in Figure 12. The power intensity of the vertical (z-direction) acceleration of the differential case is presented for different oil temperatures and at the characteristic frequencies that were identified in the results presented earlier. The clear trend is that the severity of oscillations decreases as temperature increases. This is particularly the case for the lateral sway mode of the driveline/rear axle $(240 \mathrm{~Hz})$ and for the wind-up S-bending mode of the Hotchkiss leaf springs $(356 \mathrm{~Hz})$. There also seems to be a threshold at the region of $65^{\circ} \mathrm{C}$, above which the vibration intensity decreases dramatically. The above observations confirm the hypothesis that an increase in gear pair friction reduces oscillations. The temperature of the differential oil sump reached an upper limit thermal balance for the driving conditions of the experiment and, therefore, it was not possible to obtain experimental measurements for temperatures higher than $68^{\circ} \mathrm{C}$.

\section{Conclusions}

A combination of experimental and numerical analysis for axle whine conditions of a rear wheel drive light truck is presented. The results are in line with the supposition 
made; increasing bulk oil temperature reduces film thickness in gear teeth pair conjunctions, thus increase friction and hence dissipate more of the errant vibration energy. This is effective for characteristic vibrations, which are functions of generated meshing forces. They include the meshing frequency and modal responses that are induced by generated contact forces. It has little or no effect on the transmitted engine order harmonics or indeed modes associated with component compliances (higher frequencies). However, it has already been shown in literature that these frequencies (at the extremities of the spectrum) are not the cause of axle whine, as perceived.

Axle whine problem is, therefore, likely to be at lower oil temperatures at specified coasting operating conditions, usually at higher speeds. This is a major conclusion if the results obtained from the test vehicle and model predictions are considered as representative of the vehicle-type population. Therefore, there is a causal relationship between lubrication and axle whine control. The differential oil viscosity affects axle whine by moderately reducing the radiated noise. Nevertheless, lubricant can be only regarded as another palliative measure, not a root cause solution. In the present study, a causal relationship is established between axle whine appearance/persistence and the flexural mode response of system components. Thus, the conclusions of this work can be extended to other rear wheel drive vehicles, since the approach followed is quite generic. However, it is prudent to undertake additional tests on a sample of vehicles to ascertain these findings, as well as to note any deviations due to variable built quality in a mass manufacture environment.

Most reported investigations on the axle whine phenomenon in open literature make use of test rigs which purport to replicate vehicle axle whine conditions. An advantage of this work is that the predicted modal responses can be correlated directly with in situ vehicle conditions with axle whine radiated sound. The multi-body model developed is qualitatively correlated against the experimental results. However, an accurate quantitative study should consider the effect of lubrication in the hypoid gears (through in-depth study of generated gear teeth contact forces, lubricant film thickness and thermal effects). It has been recently observed [22] that the gear teeth loss of contact causes axle whine oscillations. As a next step, the multi-body model that includes component flexibility should be used to correlate vibration characteristics (mode shapes) to gear teeth pair separations/loss of contact.

\section{Acknowledgements}

The authors wish to express their gratitude to Ford Motor Company for supporting this research project.

\section{References}

[1]- Rahnejat, H., Multi-body dynamics: vehicles, machines and mechanisms, PEP(IMECHE) and SAE Co-publishers, London, UK / Warrendale Pa, USA, 1998.

[2]- Dunn, A., Lim, T. and Houser, D. Methods for researching gear whine in automotive transaxles, SAE, 1999-01-1768, 1999.

[3]- Colabawala, M., Sorenson, J. and Houser, D. An experimental procedure for characterisation of gear whine noise in a variety of vehicle applications. SAE, 200301-1488, 2003.

[4]- Becker, S. and Yu, S. Objective noise rating of gear whine. SAE, 1999-01-1720, 1999.

[5]- Kim, S.J. and Lee, S.K. Experimental Identification of a gear Whine Noise in the Axle System of a Passenger Van. International Journal of Automotive Technology, 2007, 8(1), 75-82. 
[6]- Headley, J. and Liu, K. Test Methodology to Reduce Axle Whine in a 4WD Vehicle. SAE, 2005-01-2403, 2005.

[7]- In-Soo, S. and Jeff, O. Drivetrain Torsional and Bending Vibration for a RWD Vehicle Interior Noise Development, SAE, 2003-01-1496, 2003.

[8]- Gehringer, M. Application of Experimental Transfer Path Analysis and Hybrid FRF-Based Substructuring Model to SUV Axle Noise, SAE, 2005-01-1833, 2005

[9]- Townsend P.D. Dudley's Gear Handbook $2^{\text {nd }}$ ed., PEP McGraw-Hill Inc. 1991.

[10]- Kanda, Y. and Hatamura, K. Analytical Approach of Transmission Gear Noise, JSME, 2001-11-15, 126-131, 2001.

[11]- Sun, Z., Steyer, G., Meinhardt, G. and Ranek, M. NVH Robustness Design of Axle Systems, SAE, 2003-01-1492, 2003.

[12]- Lee, Y. and Kocer, F. Minimize Driveline Gear Noise by Optimization Technique, SAE, 2003-01-1482, 2003.

[13]- Abe, T., Bonhard, B., Cheng, M., Bosca, M., Kwasniewicz, C. and Na, L. High Frequency Gear Whine Control by Driveshaft Design Optimization, SAE, 200301-1478. 2003.

[14]- Krishnaswami, R., Defore, M., Hildebrand, D., Metcalf, J. and Sell, D. Gear Whine Improvements for an Automatic Transmission through Design Retargeting and Manufacturing Variability Reduction, SAE, 2001-01-1505, 2001.

[15]- Mori, K. and Shibata, Y. Optimum Design of Hypoid Gear Dimension and

Tooth Surface, SAE, 2003-01-0680, 2003.

[16]- Saunders, T. 2005, 'The characterisation of rear axle gear whine in commercial vehicles', MSc thesis, University of Hertfordshire

[17]- Lahey, H., Steffens, C. and Schultz, C. Simulation Method for Geartrain NVH Assessment and Optimization, SAE, 2001-01-1593, 2001.

[18]- Theodossiades, S., Gnanakumarr, M., Rahnejat, H. and Menday, M. Mode Identification in Impact Induced High Frequency Vehicular Driveline Vibrations Using a Elasto-multi-body Dynamics Approach, Proc. IMechE, Part K: J. Multi-body Dynamics, 2004, 218, 81-93.

[19]- Ando, K., Kanda, Y., Fujita, Y., Hamdi, M.A., Defosse, H., Hald, J. and Morkholt, J. Analysis of High Frequency Gear Whine Noise by Using an Inverse Boundary Element Method, SAE, 2005-01-2304, 2005.

[20]- Godano, P. and Horak, J. Use of the Reciprocity Principle for Vehicle Airborne Transfer Quantification, SAE, 2005-01-2404, 2005

[21]- Gagliardini, L., Hamdi, M.A. and Defosse, H. Noise Radiation Model of a Powertrain Using an Inverse Boundary Element Method and Projection on Wave Envelope Vectors, SAE, 2003-01-1697, 2003.

[22]- Koronias, G., Theodossiades, S., Rahnejat, H. and Saunders, T. Vibrations of differential units in light trucks. The 1st International Conference on Multibody System Dynamics, Lappeenranta, 2010.

[23]- Autosignal v1.7 Reference Manual, 2003, Systat software Inc.

[24]- Torrence, C. and Compo, G. P. A practical guide to wavelet analysis. Bulletin of the American Meteorological Society, 1998, 79(1), 61-78.

[25]- Nakaji, Y., Satoh, S., Kimura, T., Hamabe, T., Akatsu, Y and Kawazoe, H. Development of an active control engine mount system, Vehicle System Dynamics, 1999, 32, 185-198.

[26]- Kim, S.J., Lee, J.Y. and Lee, S.K. Noise Refinement of a Vehicle by Reduction of the Axle Gear Whine Noise Based on Structural Modification Using FEM and BEM, International Journal of Automotive Technology, 2007, 8(5), 605-614. 

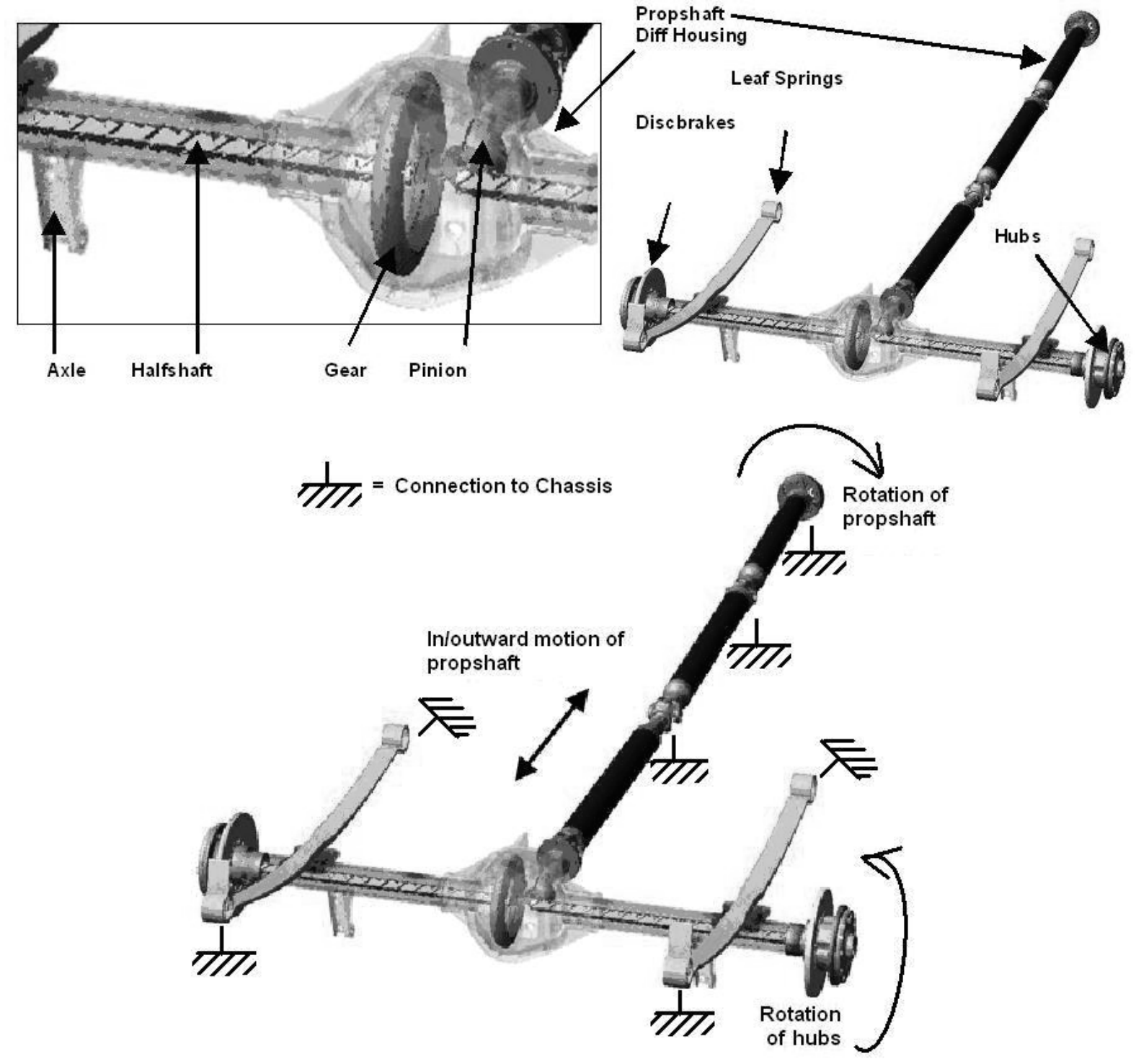

Figure 1: The elasto-multi-body drivetrain model in the ADAMS environment: (reaction points and primary motions of the drivetrain components are also shown) 

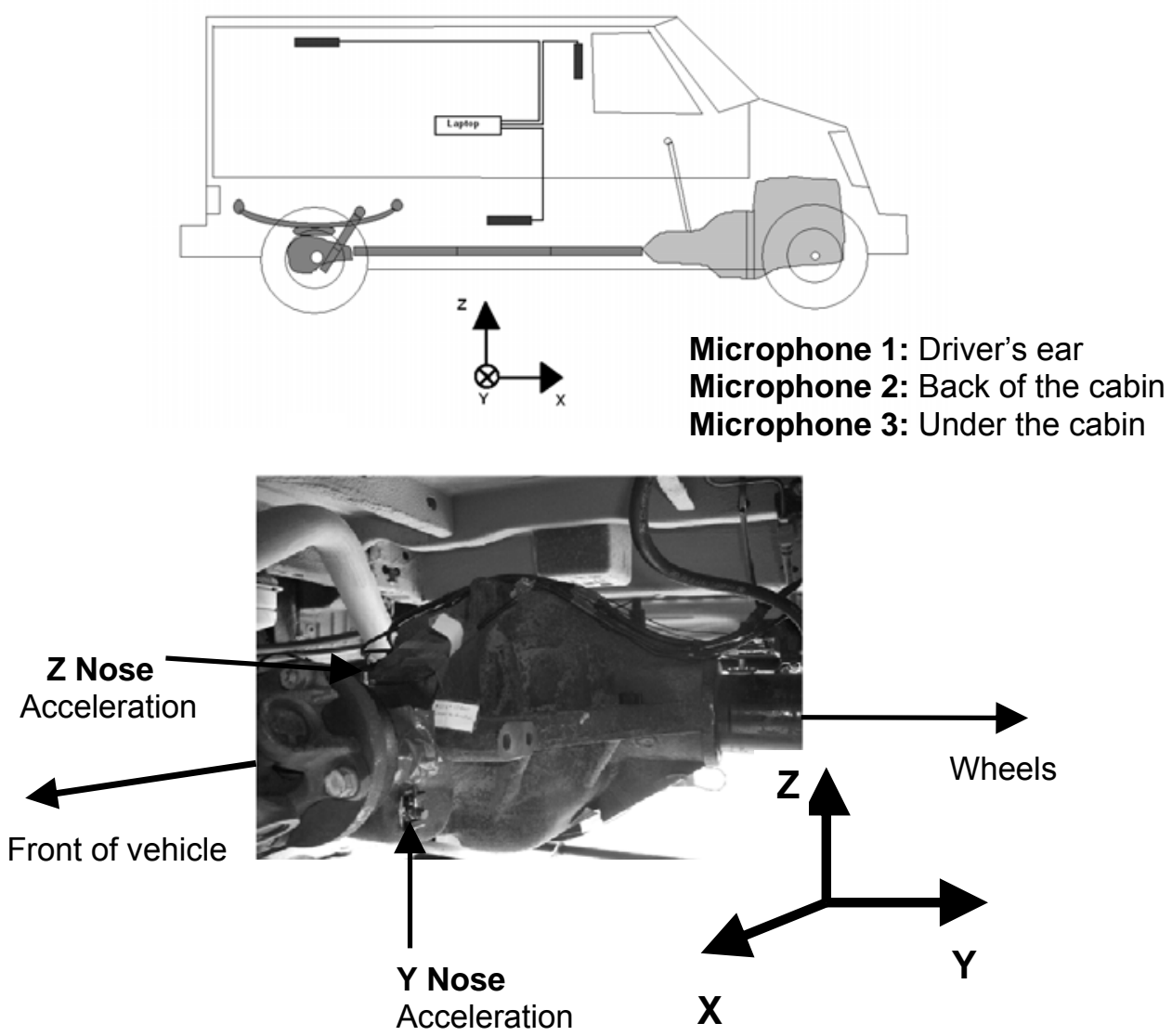

Figure 2: Instrumentation and experimental set up in the examined light truck 


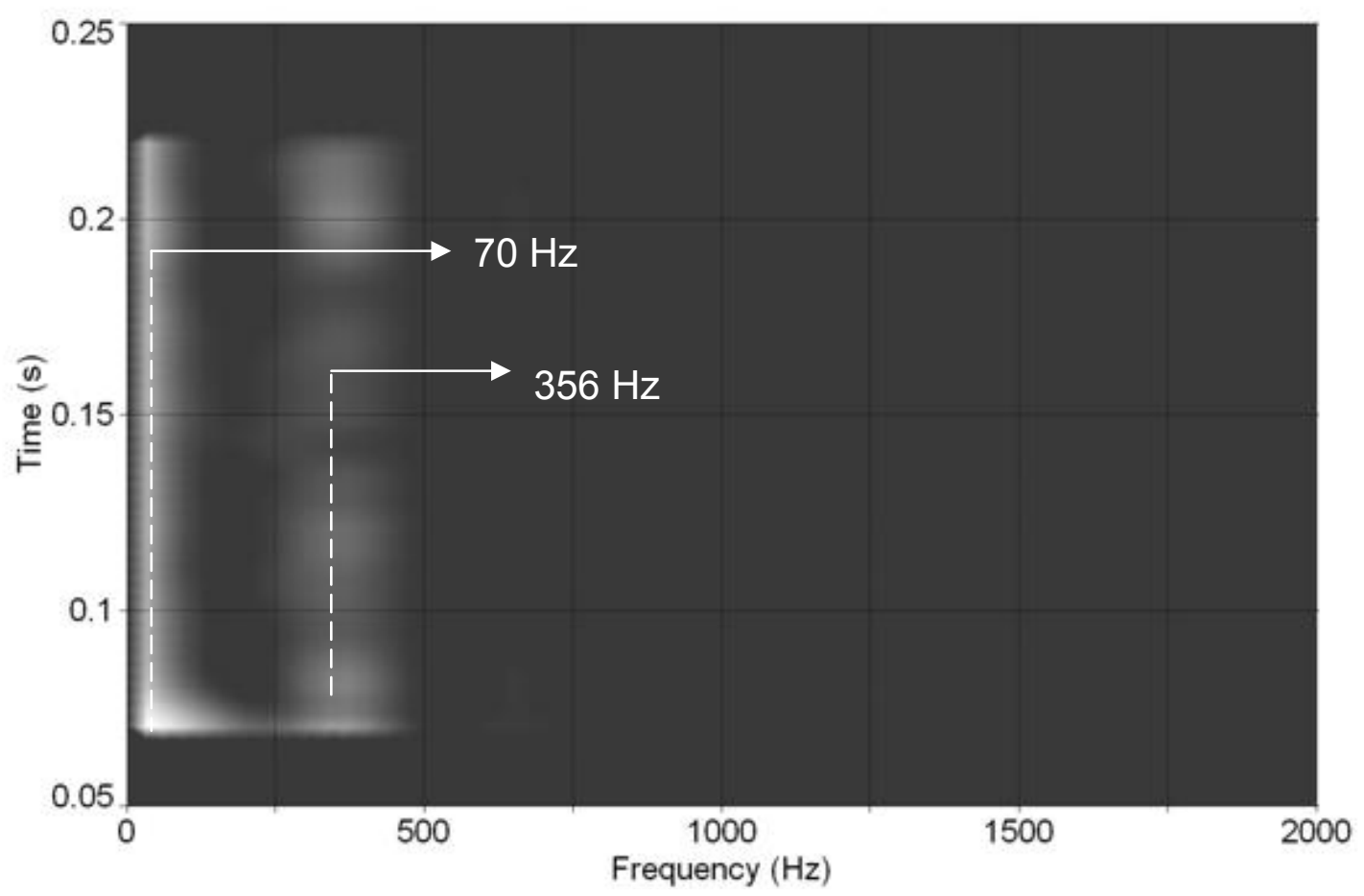

Figure 3: Wavelet of the rear cabin microphone noise signal (bulk oil temperature of $51^{\circ} \mathrm{C}$ )

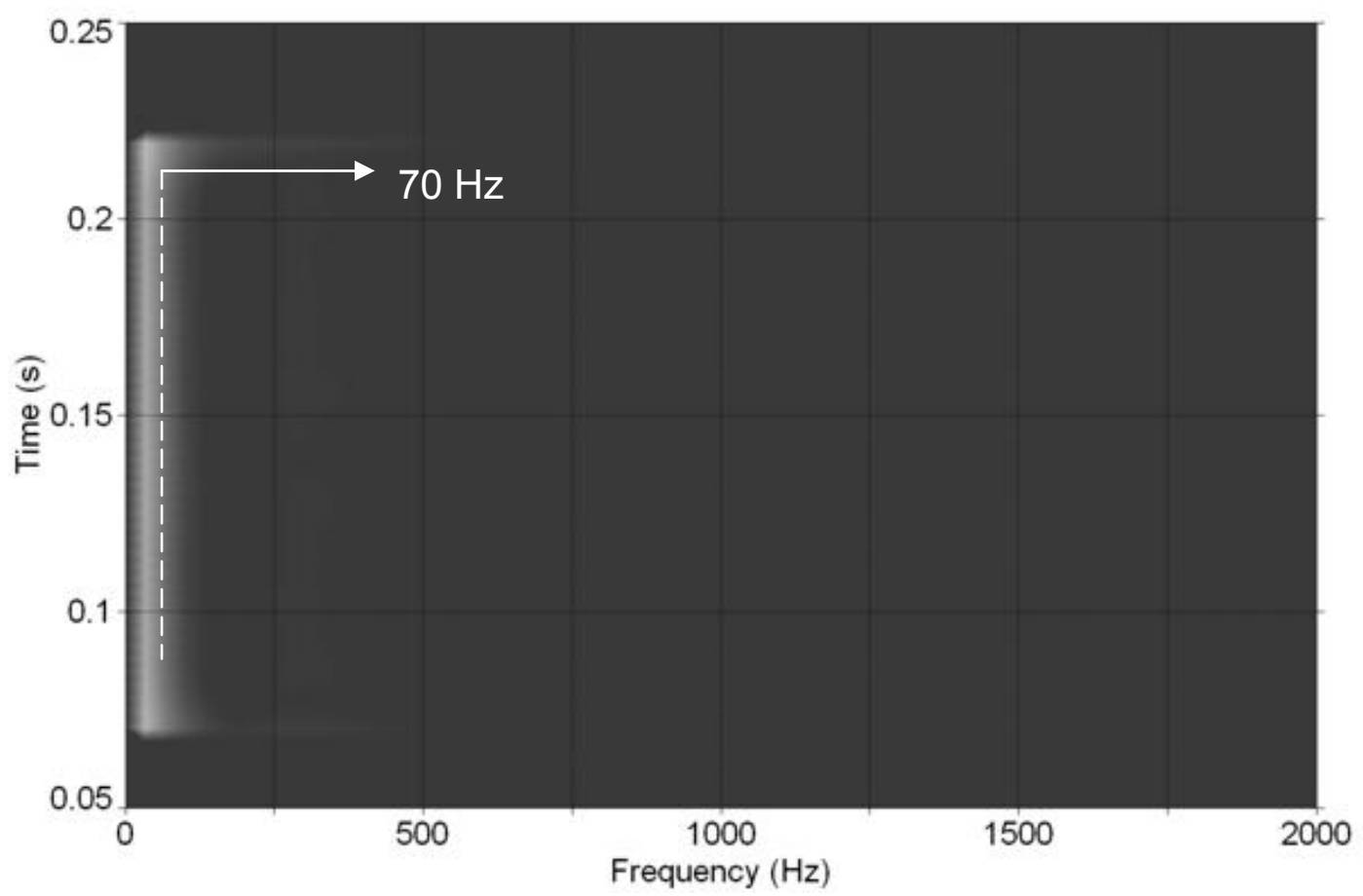

Figure 4: Wavelet of the microphone noise signal near the driver's in-board ear (bulk oil temperature of $51^{\circ} \mathrm{C}$ ) 


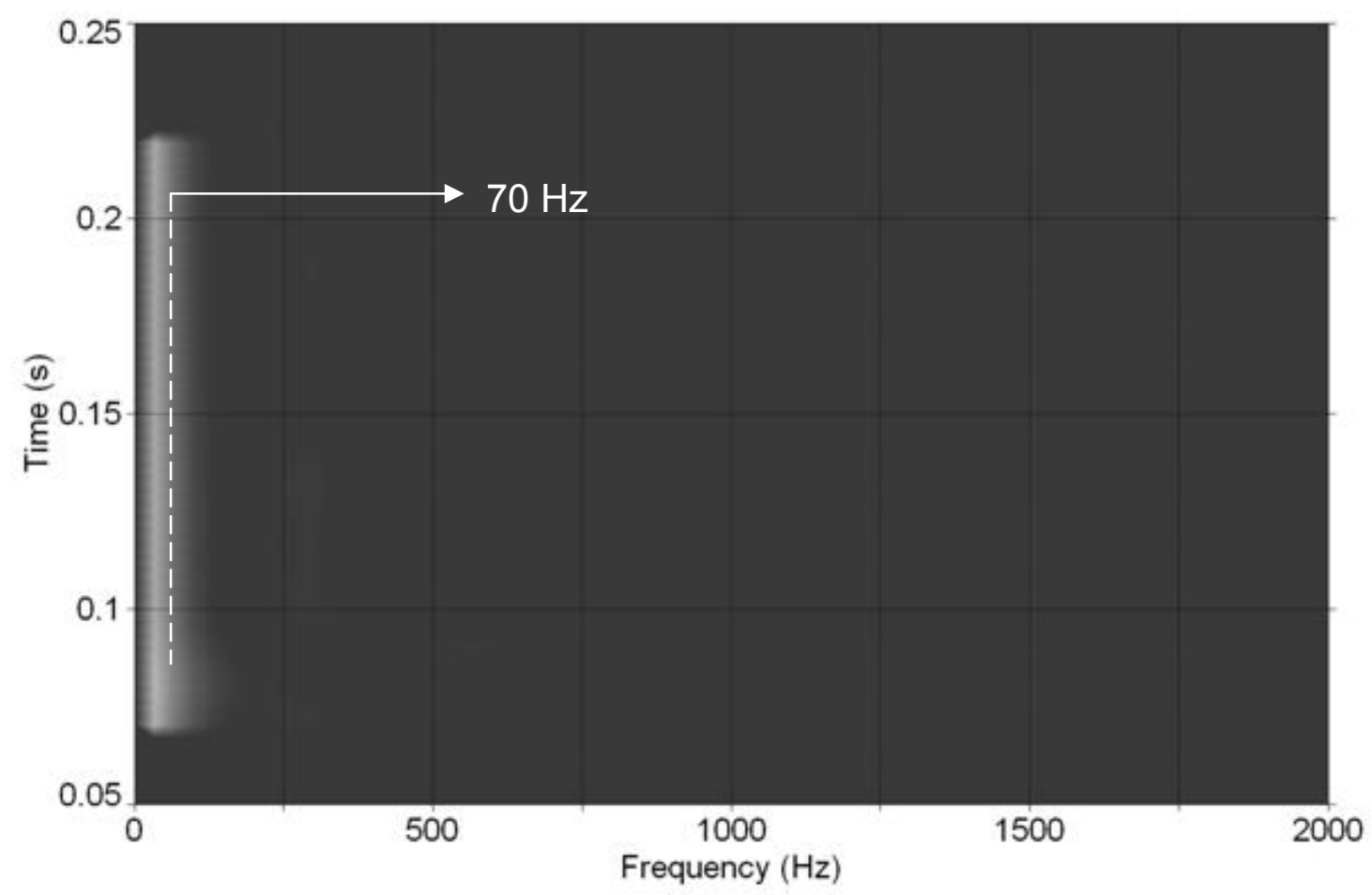

Figure 5: Wavelet of the microphone noise signal near the differential unit (bulk oil temperature of $51^{\circ} \mathrm{C}$ )

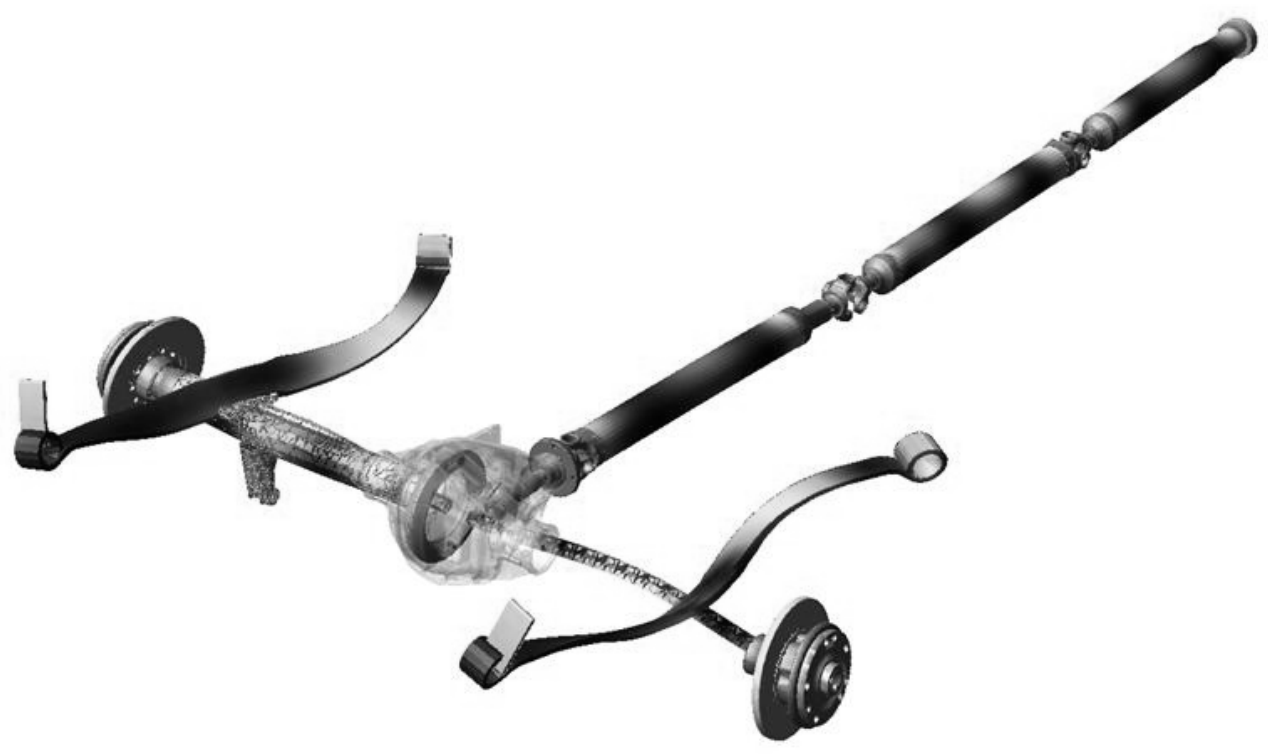

Figure 6: The drivetrain model: Wind-up S-bending mode of the Hotchkiss leaf springs accompanied by twist of the rear axle $(356 \mathrm{~Hz})$ 


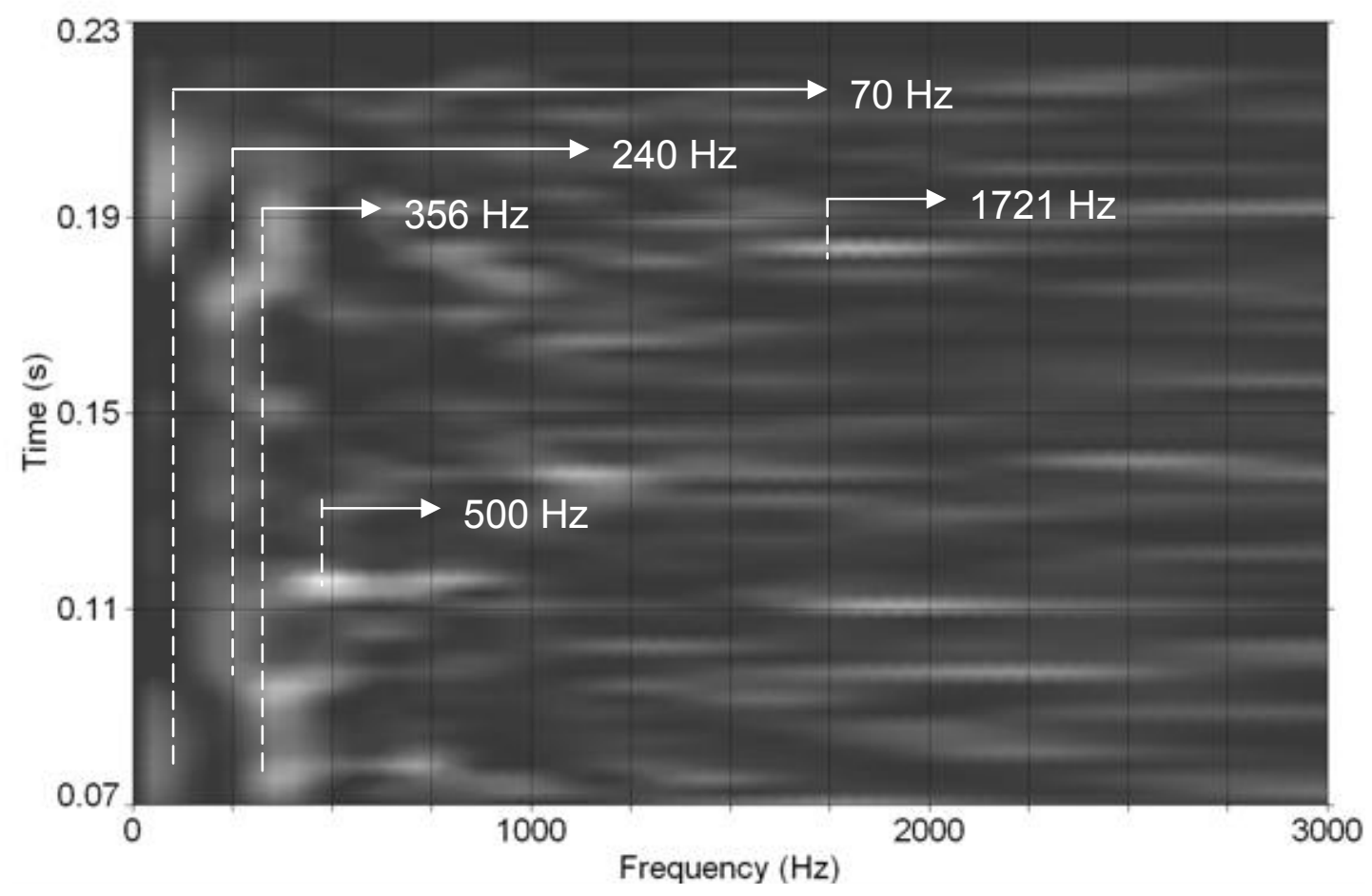

Figure 7: Wavelet of the vertical acceleration signal near the differential nose (bulk oil temperature of $51^{\circ} \mathrm{C}$ )

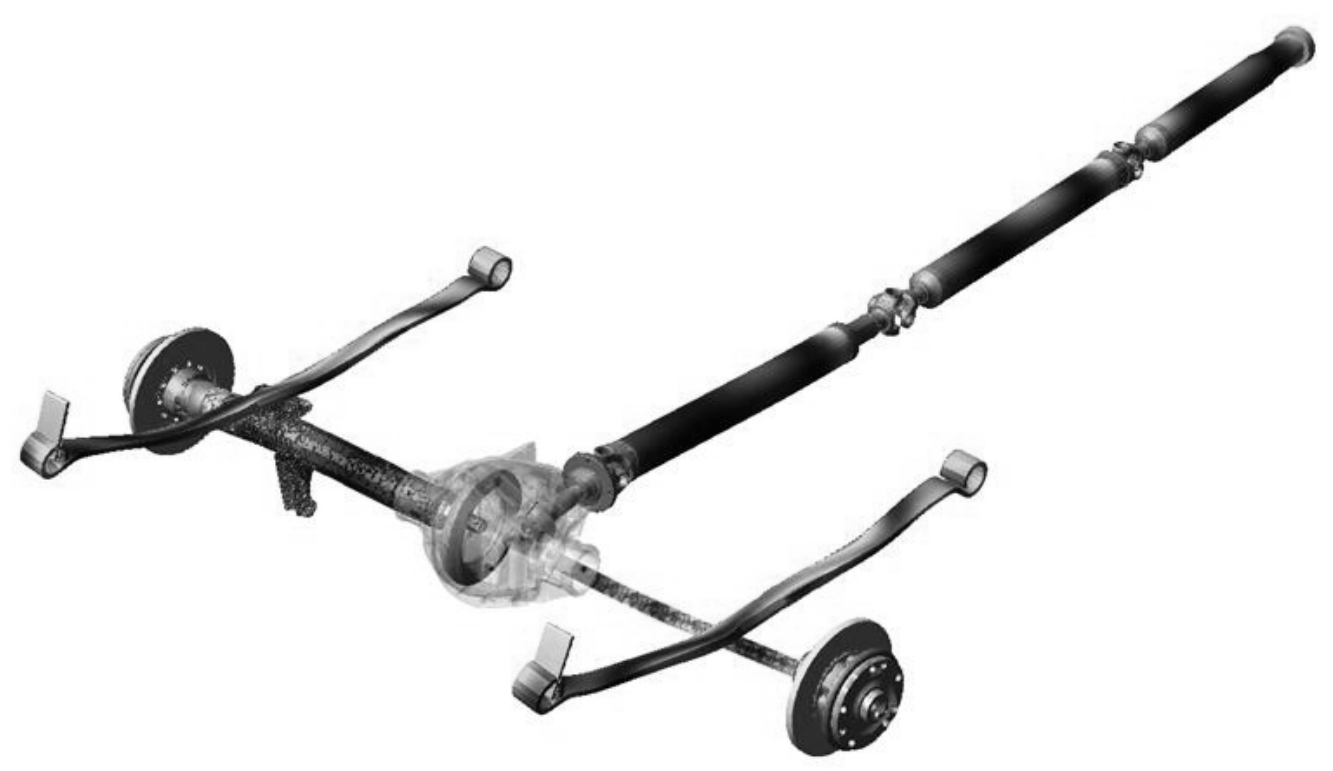

Figure 8: The drivetrain model: Wind-down mode of leaf springs with untwist of the rear axle $(509 \mathrm{~Hz})$ 


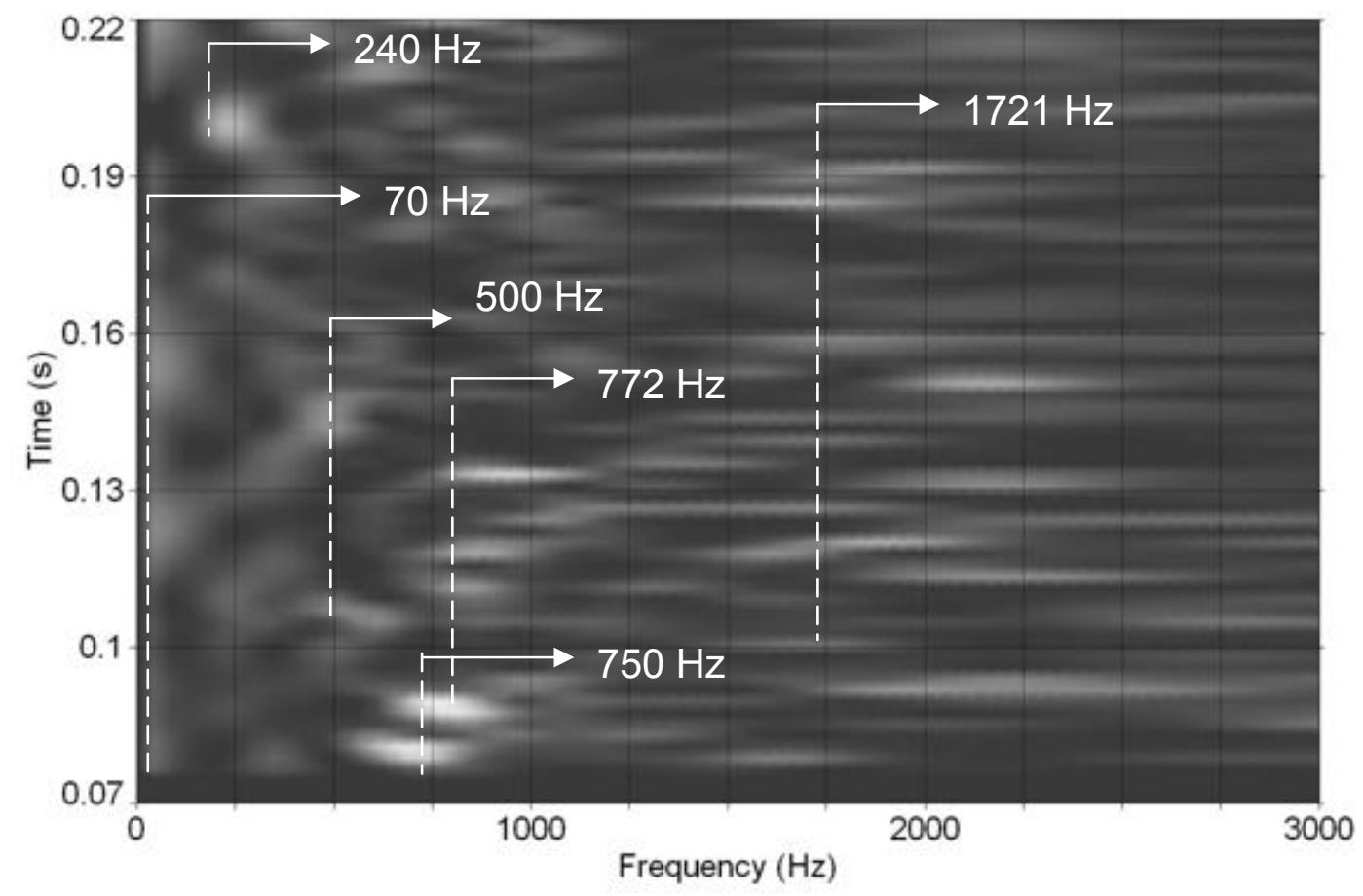

Figure 9: Wavelet of the lateral acceleration signal near the differential nose (bulk oil temperature of $51^{\circ} \mathrm{C}$ )

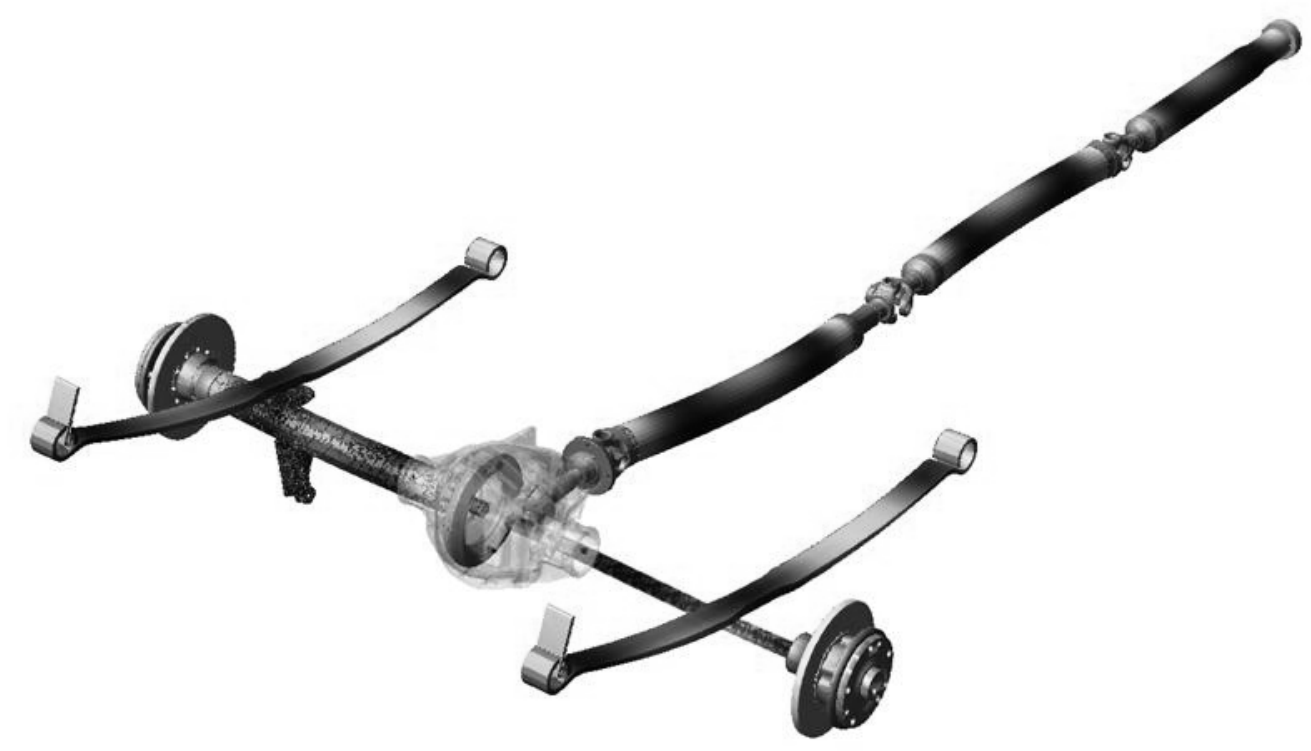

Figure 10: The drivetrain model: Lateral sway mode of the driveline and rear axle which may induce wheel tramp $(240 \mathrm{~Hz})$ 


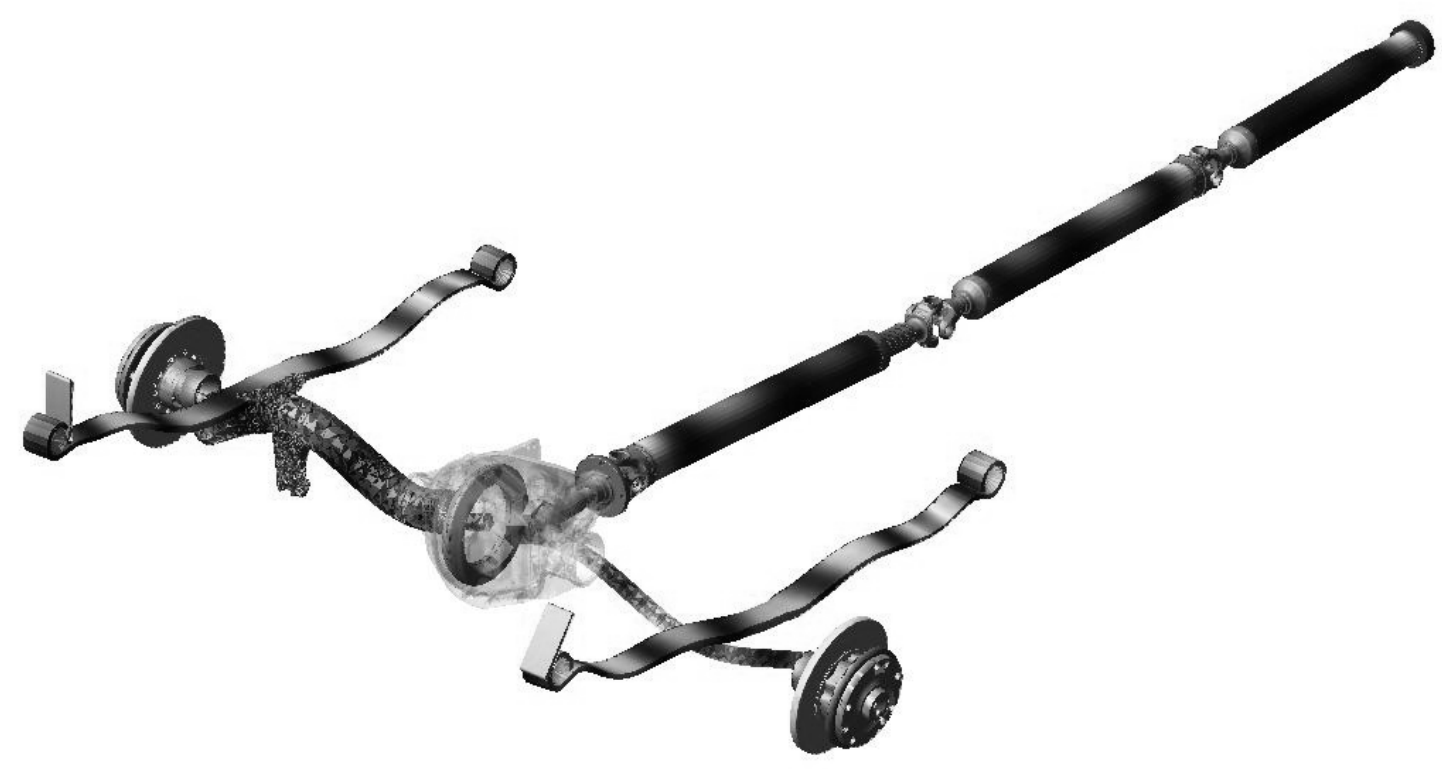

Figure 11: The drivetrain model: Butterfly mode of the rear axle with multiple leaf spring bending $(772 \mathrm{~Hz})$

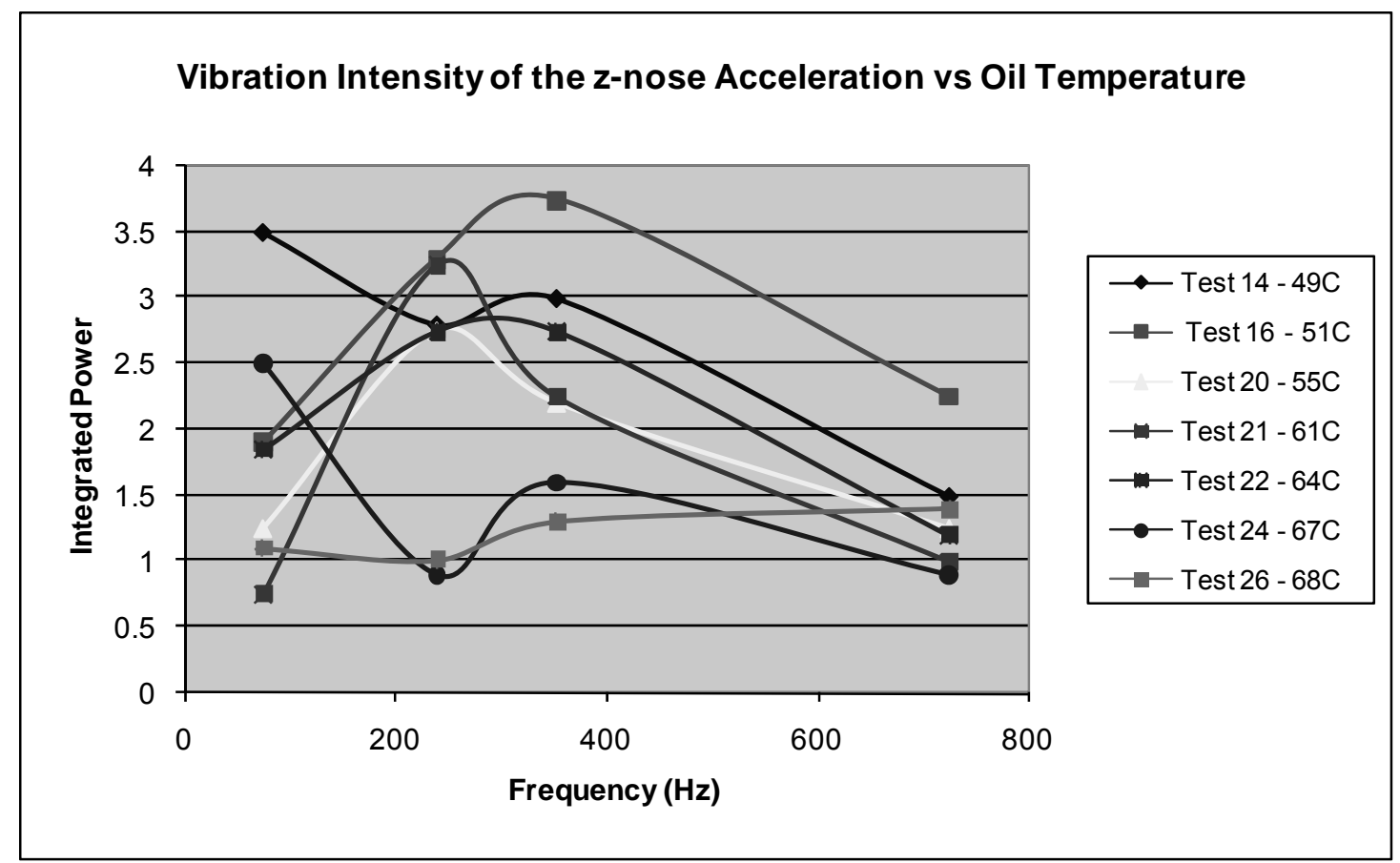

Figure 12: FFT spectral contribution of the z-direction differential nose acceleration at different bulk oil temperatures 
Table 1: Pertinent vehicle data

\begin{tabular}{|c|c|c|}
\cline { 2 - 3 } \multicolumn{1}{c|}{} & \multicolumn{1}{c|}{ Pinion } & \multicolumn{1}{c|}{ Gear } \\
\hline Number of gear teeth & 9 & 46 \\
\hline Pitch radius & $19.95 \mathrm{~mm}$ & \multicolumn{1}{c|}{$07 \mathrm{~mm}$} \\
\hline Inertia & $0.00173492 \mathrm{kgm}^{2}$ & $0.10062 \mathrm{kgm}^{2}$ \\
\hline Normal backlash (nominal) & \multicolumn{2}{|c|}{$0.075 \mu \mathrm{m}$} \\
\hline Oil properties (differential) & $\begin{array}{l}\text { SAE } 75 \mathrm{~W}-140,100 \% \text { synthetic } \\
\text { Density: } 868.74 \mathrm{~kg} / \mathrm{m}^{3}\end{array}$ \\
& $\begin{array}{l}\text { Kinematic viscosity at } 100^{\circ} \mathrm{C}: 0.0000242 \mathrm{~m}^{2} / \mathrm{s} \\
\text { Dynamic viscosity at }-40^{\circ} \mathrm{C}: 128 \mathrm{Pas} \\
\text { Viscosity index } 172\end{array}$ \\
\hline Vehicle mileage & \multicolumn{2}{|c|}{87,351 miles } \\
\hline
\end{tabular}

